\title{
The Master Plan of Fortifications as a management tool for the conservation and development of the defence heritage of Cádiz
}

\author{
C. Rubio-Bellido \& M. Ureta-Gragera \\ Department of Architectural Constructions II. University of Seville, Spain
}

\begin{abstract}
The city of Cádiz preserves numerous examples of fortifications that mark out its perimeter. Currently, the understanding of the defensive system of Cádiz as a fortified complex goes un-noticed and its maintenance is insufficient. In specific cases, the implementation of new uses in these spaces has been accomplished contributing to their preservation. However, there is a lack of a comprehensive plan that interrelates all the pieces, by means of a global understanding and a detailed enhancement. The proposed development planning, as a part of The General Urban Development Plan of 2012, is entitled as The Master Plan of Fortifications. This plan will integrate all the actions and regulations of the defence architecture of the city in order to promote the conservation and the knowledge of that heritage. In addition, it will be a reference document for future investments. Main objectives are carried out in this paper, taking into account the principles of integration, promotion, consolidation and restoration. To reach this goal, a number of strategies have been developed at various stages, which strive to achieve not only the management but also the useful preservation and environmental regeneration of those architectures. The conservation and the development of the fortified city of Cádiz is proposed in this paper through an innovative and specific management tool.

Keywords: military heritage, fortifications, sustainable development, conservation, management.
\end{abstract}

\section{Introduction}

Currently, the integration of the defence heritage as a part of the city development planning has been a challenge due to the singularity of those architectures, which 
in some cases are buried or abandoned. A few Plans were made in Spain, such as Castilla y León [1] or La Coruña [2], in order to identify and conserve the defence architecture. However, the fortifications of Cádiz are referred in The General Urban Development Plan of 2012 [3] and have been studied by the authors [4]. Therefore, the stage of identification has already been performed. Furthermore, recent investigations have outlined some strategies and opportunities for the urban regeneration of the city fortified heritage [5].

The present paper proposes a further step by means of an instrumental plan which integrates the fortifications development in the urban planning according to the current regulations in this field. To reach this goal, the authors strive to perform a thorough analysis in the legal framework and the defensive heritage of Cádiz under an overall criterion.

\section{Methodology}

A review of the legal framework concerning to heritage is needed to understand how this concept has been changing to the present day. Defence heritage has also been subject of laws and plans, so an analysis on this field has been carried out in order to lay the foundations on which this research is based.

On the second stage, the level of the fortifications integration is defined in the urban planning of the city, taking into account the available tools for the protection of Cádiz's fortified heritage.

Thirdly, considering recent research and international agreements, the goals for the fortified heritage are established by the dichotomy between conservation and development.

Finally, we discuss the development tool proposed by the General Urban Development Plan for fortified heritage: the Master Plan of Fortifications, as well as specific insights on the objectives and strategies proposed by the authors from the standpoint of the fortifications as a key role in the city's development.

\section{The heritage legal framework in Spain}

\subsection{Origins: from the "old" concept to the "protected" one}

The creation of the Academies of Fine Arts since 1752, as advisors for interventions in public buildings, was a precedent in the consideration of the artistic heritage as a value. The Royal Decree by Charles IV in 1803 is the first legal text on heritage, where the concept "monument" is defined with a value based on their characteristic of "old".

Throughout the nineteenth century, various rules are occurred individually intended to provide a legal basis for the monuments' protection. Thus, a Royal Decree of 1844 establishes the Committees of Artistic and Historic Monuments, while the Education Act of 1857 sets under the custody of the Royal Academy of Fine Arts the "Artistic Monuments of the Kingdom", and a decree of 1873 encourages municipalities and councils to avoid the destruction of public buildings "of artistic merit or historical value." 
Laws about archaeological excavations in 1911 and laws about architectural monuments in 1915 - the latter with the novelty of the necessity of declaring property as "protected" - provide the foundations of a modern protection system for heritage.

\subsection{Historical heritage laws}

The Royal Decree of 1926 refines and renews the concept of protection with the establishment of the National Artistic-Archaeological Treasury and the incorporation of cultural value to the artistic and historical one.

The Heritage Law in 1933 of the Spanish Republic is the first comprehensive law regarding national heritage. Its strength is shown in the fact that it was one of the few Republican laws maintained during Franco's time, being repealed 52 years later in the democratic era.

Spanish Historical Heritage Law 16/1985 was written in the democratic era, incorporating concepts and techniques of European experience in heritage after the Second World War, as reflected in charter of The Hague (1954), Venice (1964) and Paris (1972), as well as the willingness to integrate both urban and political heritage.

Andalusian Historical Heritage Law 1/1991 was created as a result of the transfer of cultural competence of the State to the regions, raised by the democratic Constitution in 1978. The General Inventory of Andalusian Historical Heritage was established as a part of that law. The Spanish Historical Heritage Law remains as a common framework.

Andalusian Historical Heritage Law 14/2007 replaces the Law of 1991. It is the current law for Andalusian Heritage, incorporating the experience of 15 years of regional management and European guidelines on heritage, required after the accession of Spain in 1986 to the European Union and new trends in the study, protection and promotion of heritage.

\section{Defence heritage plans}

In addition to general legislation on heritage, the defensive architecture has been the specific object of various laws and plans, both for protection and intervention. The Castles Law of 1949 aimed to protect Spanish castles and walls, after the destruction of the Civil War from 1936 to 1939. This law would be the umbrella for most of the fortifications until the Spanish Historical Heritage Law of 1985.

The European Heritage Inventory: Spain. Military Architecture Monuments 1968, prepared by the Department of Fine Arts, was published as a supplement to the Castles Law. It is the first systematic inventory of Spanish defensive architecture with over 5,000 monuments.

The Castles National Plan of 1998 promoted a program of investment in conservation and restoration of Spanish fortified heritage. With this there arose the need to update the 1968 inventory, directed by the Friends of the Castles Spanish Association, obtaining in 2008 the Europe Nostra award for this research.

The Andalusian Plan of Defensive Architecture (APDA), 2005, presented a 4year program aimed at developing a comprehensive inventory of Andalusian 
fortifications, establishing protection, conservation and intervention measures and publicising the existence of this heritage. The APDA allowed the intervention in various castles, towers and walls of Andalusia until 2011, although there was no financial support for the city of Cádiz.

The Charter of Baños de la Encina, 2006, for conservation of defensive architecture in Spain, is a document of great importance, arising from a national technical conference and proposing the establishment of criteria and methodological recommendations for the protection of, and intervention in, fortified heritage.

The National Plan of Defensive Architecture, 2006, revised in 2011, and currently in effect, assumes the methodological approaches of the Charter of Baños de la Encina in order to preserve and restore the assets of Spanish defensive architecture, and presents an investment program with three areas of intervention: city walls, bastioned structures and coastal castles and castles.

\section{The fortifications in the urban planning of Cádiz}

\subsection{Town planning in Cádiz}

In Spain, the General Urban Development Plan (GUPD) is the main legal instrument for town planning. Its first appearance dates back to the 1923 Municipal Statute, although it would not be mandatory for all towns until the approval of 1956 Spanish Land Act. The GUDP is responsible for controlling the setting-up, functioning and discipline of activities for every town use: residential and economic activity, social centres, infrastructures and open or natural areas.

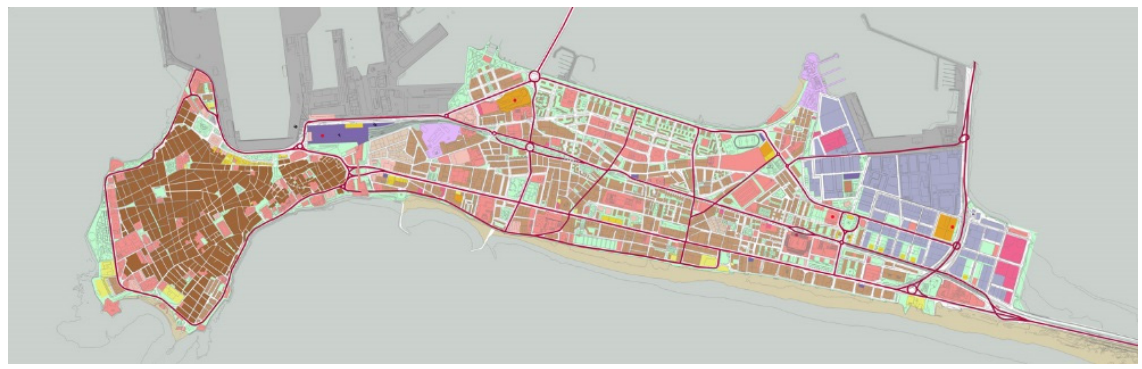

Figure 1: Plan of the city of Cádiz. General Urban Development Plan of 2012.

There have been six GUPDs throughout the history of Cádiz. The first three plans came during Franco's regime in 1948, 1961 and 1975, all of them with a developmental approach, focusing on the new residential and industrial city expansion outside the walls, and paying scant attention to the Old City and heritage problems. After the 1978 democratic return in Spain, the 1984, 1995 and 2012 GUDPs have already taken up the advocacy of Old City and heritage as one of their main goals.

In 1987, the PEPCA (Special Plan for Protecting the Old City) was approved, as a result of the 1985 Spanish Heritage Act, which made it mandatory for all 
declared historic sites, to establish the first inventory of buildings and the specific protecting rules. PEPCA served as a default rule over the Old City during the 1985 GUDP lifetime.

The 1995 and 2012 GUDPs integrate the urban and heritage regulations in a single document, consolidating the Protection Inventory and the Urban Rules as the main tools for the preservation of heritage values of the city.

\subsection{Fortifications in the GUDP inventory}

Cádiz fortifications are catalogued on the GUDP within the Military Architecture category of the Protected Buildings sub-inventory of the Architectural Heritage inventory. Along with fortifications, other non-defensive military buildings have been catalogued, as Quarters or Powder stores. Each asset has a data sheet with its main characteristics.

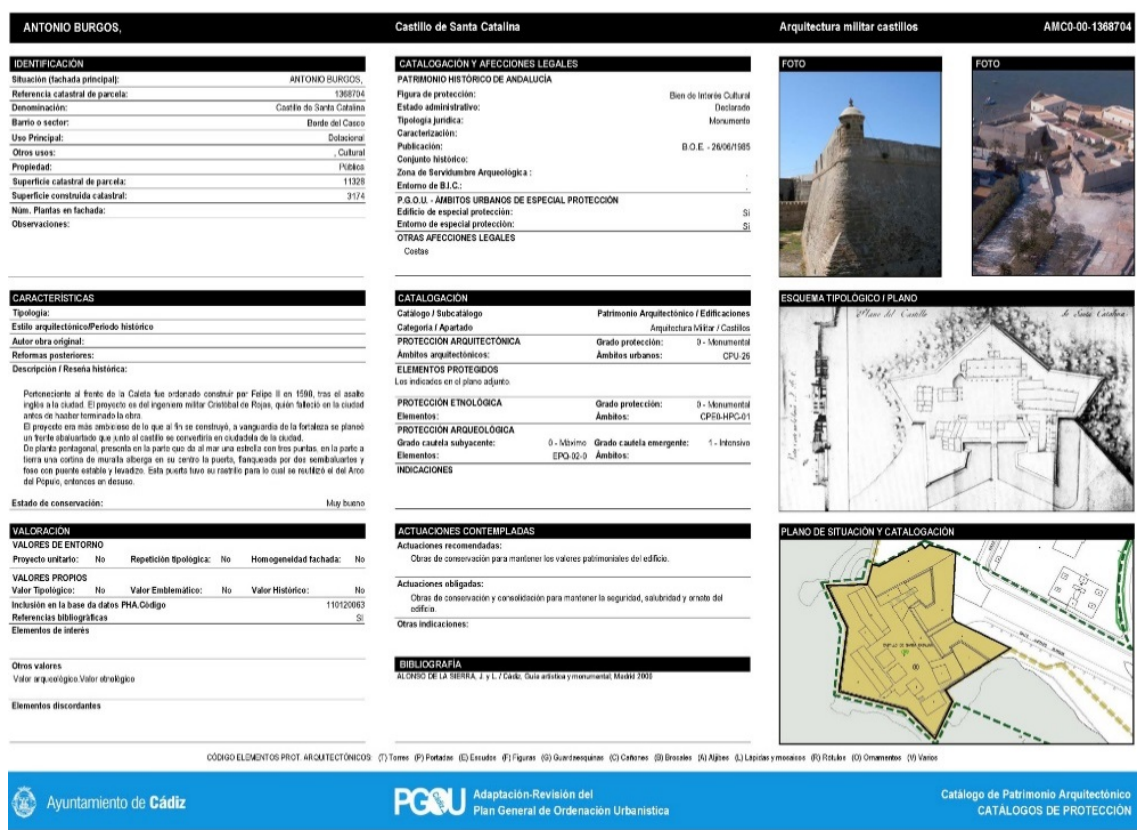

Figure 2: $\quad$ Sample of a sheet of the military architecture inventory (GUDP).

The whole fortification system has got the higher degree of protection: Monumental, in accordance with its Cultural Asset status, given by the Spanish Heritage Act. Quarters may have other protection degrees, as Singular or Preferential, depending of their heritage value. Furthermore, the totality of foundry cannons placed at the corners of old city buildings, have been included into the Protected Items Inventory, as a record of the special relationship between civilian and military elements at Cádiz. 


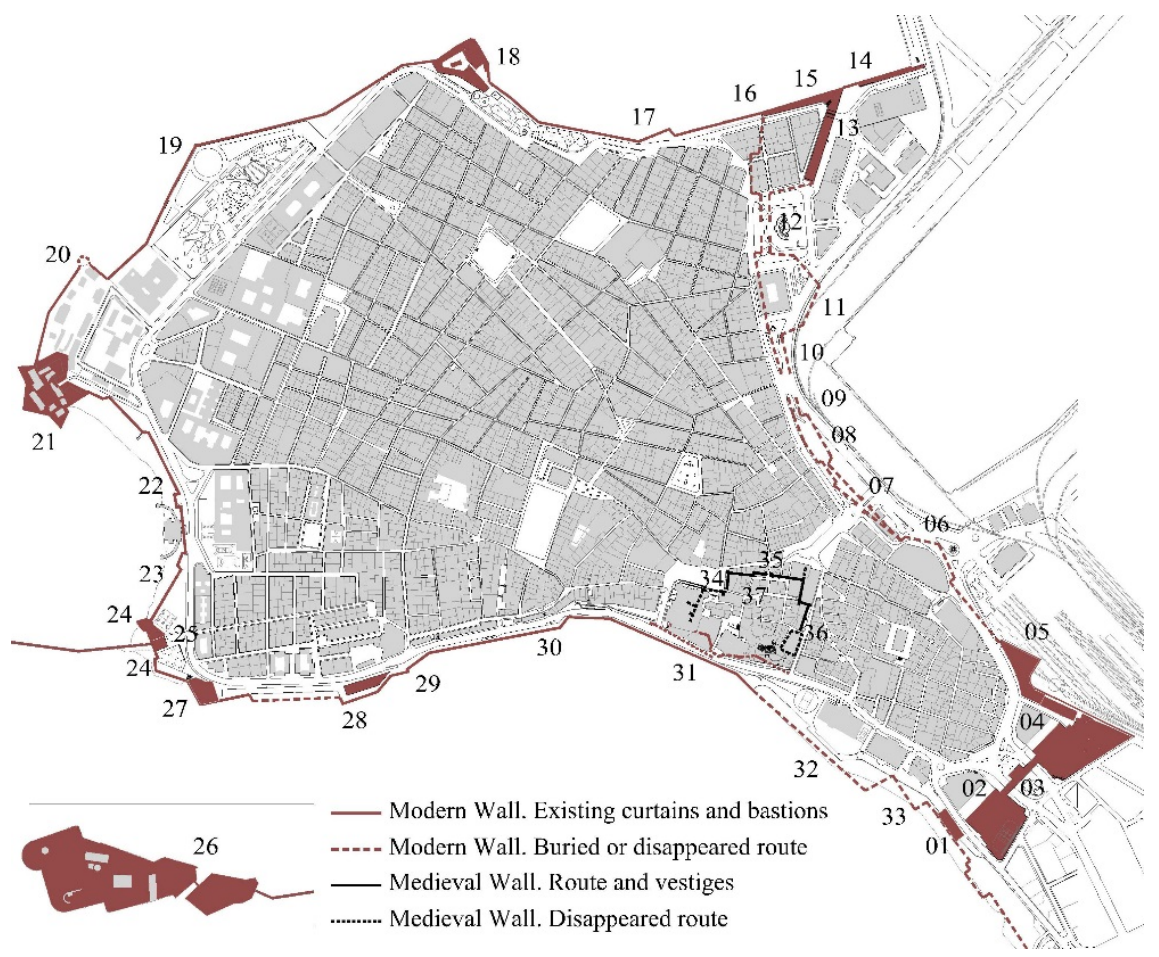

Figure 3: Plan of the fortifications of the city at the present time (own production).

\subsection{Fortifications in the Town Planning Rules}

The GUDP Town Planning Rules include a specific section for Military Architecture, where building works allowed are regulated, according to its protection degree.

As all the fortifications are included into the higher degree of protection, the Monumental, the building works allowed are those of conservation and maintenance. Exceptionally, those regeneration works approved by the regional heritage authority are allowed, which enhance the building functionality, habitability or safety, also contributing to the building values preservation.

Such works will tend towards conserving or restoring its original space distribution and organisation, not being able to change the external shape of the building. The establishment of essential technologic or hygienic-health facilities, including lifts installation will be allowed.

However, the terms of use for these buildings are regulated by the Rules according to the generic urban uses. That is why the fortifications uses are the same as the ones determined for equipment or open-air areas, since the whole Fortified Heritage is publicly owned. 
The GUDP Drafting Team, well aware of the importance of Fortified Heritage to the city and the GUDP limitations about researching work and Rules regulations, made compulsory to enlarge the GUDP specifically for the Fortified Heritage, with a complementary development plan: the Master Plan of Fortifications

\section{The goals for the fortified heritage: conservation and development}

As a research of the authors combined with some new urban interventions we try to pave the way for the future development of the fortifications. According to the Charter of Krakow 2000, "principles for conservation and restoration of built heritage", the dichotomy between conservation and development is quite important in the future of the fortifications and in the consequent significance of the city of Cádiz, that is surrounded by these kind of constructions.

As a result of the former, the goals for the fortified heritage must take into account not only the heritage as a Cultural Legacy to protect and bequeath, but also the heritage as a Local Economic Development (LED) driver.

\subsection{Conservation}

Can be realised by different types of interventions such as environmental control, maintenance, repair, restoration, renovation and rehabilitation. Any intervention implies decisions, selections and responsibilities related to the complete heritage, also to those parts that may not have a specific meaning today, but might have one in the future.

In a first step maintenance and repairs are a fundamental part of the process of heritage conservation. These actions have to be organised with systematic research, inspection, control, monitoring and testing. The restoration must be based on a range of appropriate technical options and prepared in a cognitive process of gathering knowledge and understanding of the fortifications. This may include traditional and subsequent new materials, structural investigations, graphical and dimensional analysis and the identification of historical, artistic and socio-cultural significance. All pertinent disciplines have to participate in the restoration project and the co-ordination should be carried out by qualified and well trained workgroup in conservation and restoration.

\subsection{Development}

In many cases, it also requires an appropriate new use, compatible with the existing space and significance. Work on historic buildings must pay full attention to all the periods that are present. And Adaptation to standards: accessibility, safety, energetic efficiency, based on the sustainability [6].

Any intervention should anticipate the management of change, in addition to verifying the sustainability of selected options, linking heritage issues with social and economic aspects. Moreover, involve all sectors of the population improving 
the knowledge and research as well as the educational values, taking part of an urban identity of the city.

As a final point, we have to be aware of referring to the city in its morphological, functional and structural whole, as part of its territory, its environment and surrounding landscape [7].

All these points based on the charter of Krakow 2000 can be applied to city of Cádiz by means of the Master Plan of Fortifications because the morphology of the fortifications, the conscience of the general population and the organic unity of their boundary wall.

\section{The Master Plan of Fortifications}

The General Urban Development Plan of 2012 just only makes provision for the future development of the Master Plan of Fortifications. The authors strive to carry out the objectives and the strategies for the future development of the fortified heritage of the city under the understanding of the defensive system of Cádiz as a fortified complex. This Master Plan is focused as a comprehensive project by means of a global understanding and a detailed study of each architecture.

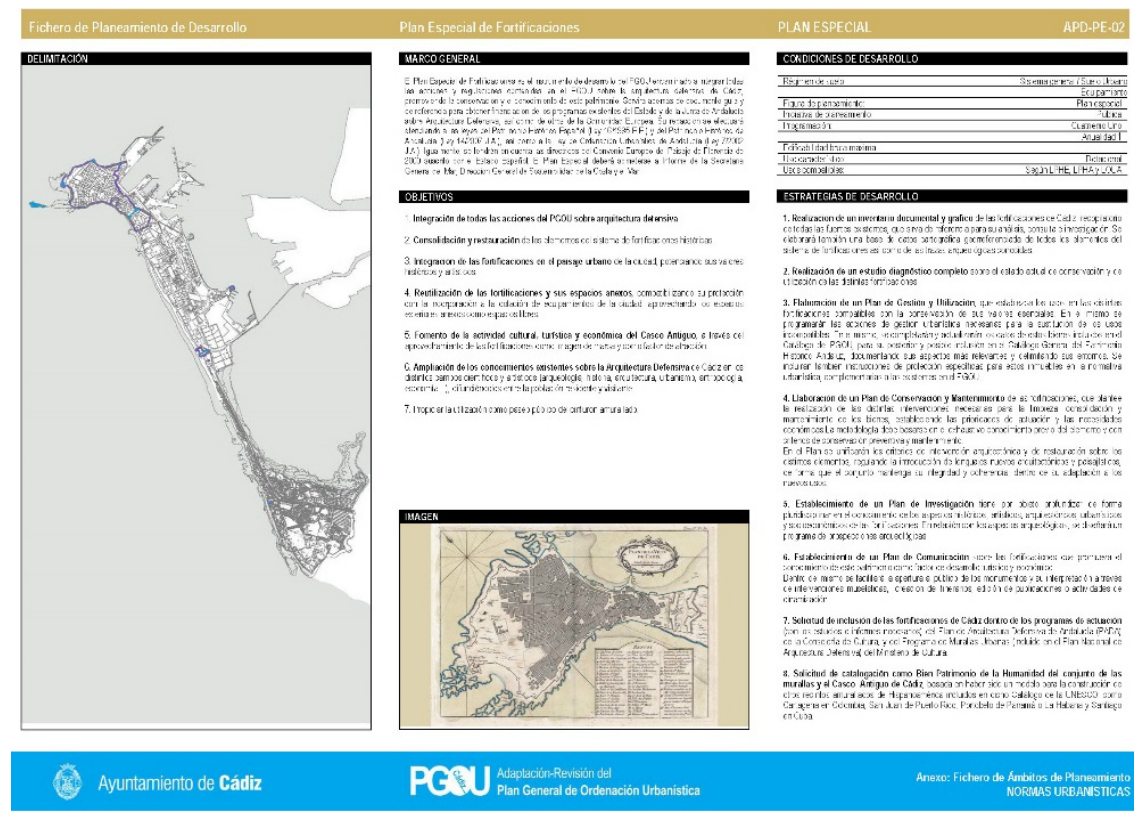

Figure 4: Main sheet of the Master Plan of Fortifications. Objectives and strategies proposed. Authors and GUPD production. 


\subsection{Objectives}

To reach this goal, the main objectives are:

1. Integration of all actions of the General Urban Development Plan on defensive architecture.

2. Consolidation and restoration of historic fortifications to integrate the fortifications in the urban landscape of the city, promoting its historical and artistic values.

3. The Reuse of the fortifications and their adjacent areas, combining their protection with the addition to the provision of facilities in the city, taking advantage of the spaces annexes as outdoor spaces.

4. Promotion of cultural tourist and economic activities in the historic city, through the use of the fortifications as brand image and as a pull factor.

5. Expansion of the existing knowledge on the defensive architecture of Cádiz in various scientific and artistic fields (archaeology, history, architecture, urban planning, anthropology, economy...), disseminating them among the local population and visitors.

6. Promotion of the use of the boundary wall as public areas.

\subsection{Strategies for the sustainable development}

1. Completing the inventory of the fortifications of Cádiz, compilation of all existing sources, as a reference for analysis and research. They also develop a georeferenced cartographic database of all the elements of the system of fortifications and known archaeological traces.

2. Conducting a full diagnosis on the state of conservation and use of the fortifications.

3. Development of a Plan for Management and Use. The uses compatible with conservation will be established. The same will be scheduled urban management actions necessary for the replacement of the incompatible uses. Its instructions will also include specific protection for these properties on the urban rules, complementary to those in the General Urban Development Plan.

4. Development of a Plan of Conservation and Maintenance of the fortifications, to raise the performance of the interventions required for cleaning, consolidation and maintenance of the property, setting policy priorities and economic needs. The methodology should be based on a thorough knowledge of these architectures and the preventive conservation criteria. The Plan criteria and restoration architectural intervention on the various elements will be unified, regulating the introduction of new architectural languages, so that it maintains its integrity and consistency within their adaptation to new uses.

5. Establishment of a Research Plan that aims to deepen the multidisciplinary knowledge of historical, archaeological, artistic, architectural, urban and socioeconomic aspects of the fortifications.

6. Establishment of a Communication Plan that promotes the fortifications knowledge of this heritage as a factor in tourism and economic development. 
7. Request for the inclusion of the fortifications of Cádiz in the programs of action (with studies and reports required) of the Andalusian Plan of Defensive Architecture (APDA), and Urban Fortified Program (included in the National Plan Defensive Architecture) of the Ministry of Culture.

8. Application for listing as World Heritage site, having been model to other fortified cities in America which are included in the UNESCO inventory, as Cartagena, San Juan, Portobello, La Habana and Santiago [8].

\section{Conclusions}

The authors present the current work for the conservation and development of the fortified complex of the city of Cádiz by means of this innovative and specific ongoing management tool. This is another document as a part of both Research and Communication Plan to promote the fortification knowledge. The proposed objectives and strategies, acting globally on the whole fortified complex, will strengthen the interaction and understanding of the diverse defensive architecture that border the city.

\section{References}

[1] Cobos, F. \& Retuerce, M. Metodología, valoración y criterios de intervención en la arquitectura fortificada de Castilla y León. Catálogo de las provincias de León, Salamanca, Valladolid y Zamora. Junta de Castilla y León, 2011.

[2] Vecoña, M. et al. Descubrir a historia. Plan director das fortalezas transfronteirizas do Baixo Miño. Xunta de Galicia, 2006.

[3] Galindo Riaño, A. \& Rubio-Bellido, C. The fortifications in the town planning of Cádiz. The fortifications in the town planning of Cadiz. Fortified places in the Bay of Cádiz, ed. Parma: Festival Architettura, Parma, pp. 52-65, 2013.

[4] Rubio-Bellido, C., Gallego Pérez, P. \& Llácer Pantión, R. The future of fortifications in the city of Cádiz: opportunities and strategies for an urban regeneration. WIT Transactions on the Built Environment. Volume 123, pp. 135-147, 2011.

[5] Plan General de Ordenación Urbana de Cádiz http://institucional.cadiz.es /area/PlanGeneraldeOrdenacionUrbana(PGOU)/677

[6] Rubio-Bellido, C. Sánchez-Montañés, B., Pulido-Arcas J.A. \& CabezaLainez, J.M. Techniques of environmental analysis applied to the urban heritage of Cádiz. Heritage 2012. $3^{\text {rd }}$ International Conference on Heritage and Sustainable Development, ed. Green Lines Institute, Oporto, pp. 629-637, 2012.

[7] Llácer Pantión, R. Cádiz. Caracterización de los bordes de la ciudad histórica. Universidad de Sevilla, 2008.

[8] Chías, P. \& Abad, T. Cádiz and the Caribbean: A Transatlantic Relationship. University of Alcalá, Madrid, 2011. 